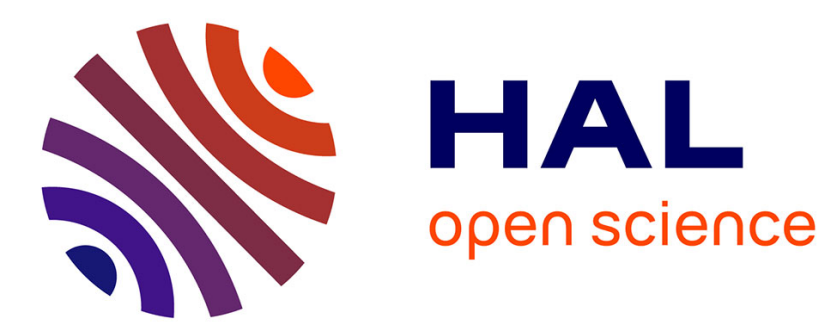

\title{
Reflexive derivations in Thulung
}

Aimée Lahaussois

\section{To cite this version:}

Aimée Lahaussois. Reflexive derivations in Thulung. Linguistics of the Tibeto-Burman Area, 2016, 39 (1), pp.49-66. 10.1075/ltba.39.1.03lah . hal-01356779

\section{HAL Id: hal-01356779 \\ https://hal.science/hal-01356779}

Submitted on 26 Aug 2016

HAL is a multi-disciplinary open access archive for the deposit and dissemination of scientific research documents, whether they are published or not. The documents may come from teaching and research institutions in France or abroad, or from public or private research centers.
L'archive ouverte pluridisciplinaire HAL, est destinée au dépôt et à la diffusion de documents scientifiques de niveau recherche, publiés ou non, émanant des établissements d'enseignement et de recherche français ou étrangers, des laboratoires publics ou privés. 
REFLEXIVE DERIVATIONS IN THULUNG ${ }^{1}$

Aimée Lahaussois

Laboratoire Histoire des Théories Linguistiques

(UMR 7597 CNRS/Université Paris Diderot)

Thulung Rai, an endangered Tibeto-Burman language spoken in Eastern Nepal, presents two derivational suffixes associated with reflexivization: $-s i$ and $-s$.

The first, $-s i$, is quite productive, found in complete paradigms, and derives reflexives, reciprocals, antipassives and anticausatives from transitive verbs (and occasionally from intransitive verbs).

The second marker, $-s$, is more difficult to analyze: it has a limited distribution in verb paradigms, only appearing with $1 \mathrm{PI}$ and $3 \mathrm{SG}$ forms, and appears in a number of different contexts: it is found with the same types of derivations as -si but also--in some cases obligatorily, in others optionally--with verbs that do not have reflexive (or related) functions. It is even found with some transitive verbs.

In this presentation, I will propose an analysis of the phenomena above based on elicited and narrative data I have collected in the field. The $-s$ in fact has multiple, albeit related, origins: it is a phonological reduction of $-s i$ in certain circumstances, while in others it appears to be an older reflexivizing suffix which has been integrated, to different degrees, into verb morphology. With transitives, it appears to be a trace reflecting the complex derivational history of verbs which are derived from intransitives.

Key words: reflexive, Thulung Rai, Kiranti languages

\section{INTRODUCTION}

Thulung Rai is an oral language of the Kiranti subgroup of Tibeto-Burman, spoken in Eastern Nepal by some two thousand speakers. As is typical of the 30odd Kiranti languages, Thulung has rich verbal morphology, with a complex system of verb endings and alternating verb stems.

One productive area of study as far as Thulung verbal morphology is concerned is derivational morphology and the complex nature of transitivity in the language. In this article, I shall discuss two morphemes, $-s i$ and $-s$, both of which are associated with reflexive ${ }^{2}$ derivation, but with differences in

\footnotetext{
${ }^{1}$ I wish to thank Guillaume Jacques, Boyd Michailovsky and the anonymous reviewers for their useful comments. I also wish to thank my Thulung consultants, especially Bala Thulung and Chandra Kala Rai. This research was funded by the HimalCo project (ANR-12-CORP0006).

${ }^{2}$ In this paper I use the term reflexive for the morpheme $-s i$, referring to a cluster of functions marked by this single morpheme with the reflexive being the most common. This is in accordance with the general practice in descriptions of Kiranti languages, where most linguists use the term reflexive for the cognate morpheme rather than middle marker. There are exceptions, such as Opgenort, who uses the term middle marker in his descriptions of the Jero (2005) and Wambule (2004) languages, and LaPolla (2004) who encourages linguists working on Tibeto-Burman languages to take into account the possibility that it is middle and not reflexive marking which is found in their languages.

Some uses of $-s i$ in Thulung indeed resemble what in other languages has been referred to as middle marking: this is the case of Thulung cognition and emotion verbs for which the addition of -si results in what Palancar (2006: 617-18) calls a 'middle of intensity' (and illustrates with the same pair of verbs as in examples 7 and 8 in the present article). I choose to categorize
} 
productivity, distribution, and semantico-syntactic features. I begin with a presentation of Thulung verbal morphology, to familiarize the reader with the verb root template and the verb stem alternation found in the language, a necessary starting point for understanding the functions of morphemes $-s i$ and $-s$. Each morpheme is discussed in turn, with the paradigmatic distribution of the morpheme (which is different for the two morphemes), derivational (and other) functions, and the types of verbs which can take the morpheme. The morphemes are discussed separately because of the overlap between the two: both -si and -s are used to derive reflexives from (mostly) transitive verbs, but $-\mathrm{s}$ is also found in other, contexts which diachronically related to reflexive derivation.

\section{THE THULUNG VERB}

This section briefly presents Thulung verb morphophonology. Similarly to other Kiranti languages (Michailovsky 1975), the syllable template for the basic Thulung verb is $\left(C_{i}\right)(L)(G) V\left(C_{f}\right)$, where $C_{i}$ is an initial consonant (see Lahaussois 2003:1 for the list of possible $C_{i}$ 's), $L$ is a liquid ( $(r$ or 1$)$, $G$ is a glide (w or j), $V$ is a vowel, and $\mathrm{C}_{\mathrm{f}}$ is a final consonant. The possible $\mathrm{C}_{\mathrm{f}}$ 's in Thulung are $\mathrm{pt} \mathrm{k} \mathrm{mn} \mathrm{y}$ $1 \mathrm{r}$.

Verbs with open syllable roots or with a $C_{f}$ of $-m,-n,-n,-r,-1$ are invariant, whereas other verbs have multiple stems. For the latter, two stems are found: one has the same shape as the verb root (in other words retaining the $\mathrm{C}_{\mathrm{f}}$ ), while the other stem has undergone either nasalization of the $\mathrm{C}_{\mathrm{f}}$ (this applies to $\mathrm{C}_{\mathrm{f}} \mathrm{s}$ - $\mathrm{p}$ and t) or elision of the $C_{f}$ (this applies to $C_{f}^{\prime} s-k$ and $-n$ ). These stems appear in paradigmatically predictable combinations with the agreement markers, which are distinct for transitive and intransitive paradigms. Simplified ${ }^{3}$ agreement marker paradigms are presented in Tables 1 and 2.

such verbs under the 'antipassive' label, highlighting the fact that there is a group of verbs for which derivation with -si results in a specific type of demotion of the P. In other cases, the data presented here as reflexive might be interpreted as middle by others: this is the case of grooming verbs, for example, which are considered reflexive here according to the formula A, $\mathrm{P}>\mathrm{S}$.

${ }^{3}$ Transitive endings encode agent and patient person and number, resulting in very large paradigms. Considering that in the vast majority of examples drawn from a narrative corpus the patient is $3 \mathrm{SG}$, the endings provided in Table 1 are those for a default $3 \mathrm{SG}$ patient. 


\begin{tabular}{|c|c|c|}
\hline & NPST & $P S T$ \\
\hline $1 \mathrm{SG}>3 \mathrm{SG}$ & $-\mathrm{u} /-\mathrm{pu}$ & -uto \\
\hline $1 \mathrm{DI}>3 \mathrm{SG}$ & - tsi & $-\mathrm{ttsi}$ \\
\hline $1 \mathrm{DE}>3 \mathrm{SG}$ & -tsuku & -ttsoko \\
\hline $1 \mathrm{PI}>3 \mathrm{SG}$ & -i/-di & -di \\
\hline $1 \mathrm{PE}>3 \mathrm{SG}$ & $-\mathrm{ku}$ & -ttoko \\
\hline $2 \mathrm{SG}>3 \mathrm{SG}$ & - na & -nna \\
\hline $2 \mathrm{DU}>3 \mathrm{SG}$ & -tsi & $-\mathrm{ttsi}$ \\
\hline $2 \mathrm{PL}>3 \mathrm{SG}$ & - ni & -nni \\
\hline $3 \mathrm{SG}>3 \mathrm{SG}$ & $-y /-d y$ & $-d y$ \\
\hline $3 \mathrm{DU}>3 \mathrm{SG}$ & - tsi & $-t$ tsi \\
\hline $3 \mathrm{PL}>3 \mathrm{SG}$ & $-\mathrm{mi}$ & $-\mathrm{mri}$ \\
\hline
\end{tabular}

Table 1. Transitive endings

\begin{tabular}{|c|c|c|}
\hline & NPST & PST \\
\hline $1 \mathrm{SG}$ & - nu & -yro \\
\hline 1DI & $-t s i$ & -ttsi \\
\hline $1 \mathrm{DE}$ & -tsuku & -ttsoko \\
\hline 1PI & -i/-di & -di \\
\hline $1 \mathrm{PE}$ & $-\mathrm{ku}$ & -ttoko \\
\hline $2 \mathrm{SG}$ & - na & -nna \\
\hline $2 \mathrm{DU}$ & -tsi & -ttsi \\
\hline $2 \mathrm{PL}$ & -ni & -nni \\
\hline $3 \mathrm{SG}$ & $-\varnothing$ & -da \\
\hline $3 \mathrm{DU}$ & - tsi & -ttsi \\
\hline $3 \mathrm{PL}$ & $-\mathrm{mi}$ & -mri \\
\hline
\end{tabular}

Table 2. Intransitive endings

Table 3 presents the stem distribution for a transitive verb with $C_{f}-p$, alternating between stems wap- (shaded cells) and wam-. Note that for all verbs presented in this article, the verbs will be given in infinitive form alongside their root, presented in || .

\begin{tabular}{ccc}
\hline $\begin{array}{c}\text { wammu } \mid \text { wap } \mid, \\
\text { scoop water }\end{array}$ & NPST & $P S T$ \\
\hline $1 \mathrm{SG}>3 \mathrm{SG}$ & wap-u & wap-to \\
$1 \mathrm{DI}>3 \mathrm{SG}$ & wam-tsi & wap-tsi \\
$1 \mathrm{DE}>3 \mathrm{SG}$ & wam-tsuku & wap-tsoko \\
$1 \mathrm{PI}>3 \mathrm{SG}$ & wap-di & wap-di \\
$1 \mathrm{PE}>3 \mathrm{SG}$ & wam-ku & wap-toko \\
\hline $2 \mathrm{SG}>3 \mathrm{SG}$ & wam-na & wap-na \\
$2 \mathrm{DU}>3 \mathrm{SG}$ & wam-tsi & wap-tsi \\
$2 \mathrm{PL}>3 \mathrm{SG}$ & wam-ni & wap-ni \\
\hline $3 \mathrm{SG}>3 \mathrm{SG}$ & wap-dy & wap-dy \\
$3 \mathrm{DU}>3 \mathrm{SG}$ & wam-tsi & wap-tsi \\
$3 \mathrm{PL}>3 \mathrm{SG}$ & wam-mi & wap-miri \\
\hline
\end{tabular}

Table 3. Example of a verb stem alternation pattern

For a more complete presentation of Thulung verb morphology, see Lahaussois 2011.

\section{DERIVATION WITH - si}

The primary result of a verb undergoing derivation with $-s i$ is a reduction in its valence, most commonly leading to a reflexive reading. 


\subsection{Paradigm verbs having undergone derivation with -si}

Derivation with $-s i$ is very regular: the morpheme $-s i$ (and allomorphs ${ }^{4}$ ) is present in all forms throughout the paradigm, as seen in Table 4 . Note that this presents a contrast from what is found with the morpheme $-s$, as will be seen in Table 8 .

\begin{tabular}{lll}
\hline $\begin{array}{c}\text { khlosimu } \\
\text { |khlok-sit } \mid, \\
\text { 'return' }\end{array}$ & \multicolumn{1}{c}{ NPST } & \multicolumn{1}{c}{$P S T$} \\
\hline 1SG & $\mathrm{k}^{\mathrm{h} l o s i n u}$ & \\
1DI & $\mathrm{k}^{\mathrm{h} l o s i n t s i}$ & $\mathrm{k}^{\mathrm{h} l o s i n r o}$ \\
1DE & $\mathrm{k}^{\mathrm{h} l o s i n t s u k u}$ & $\mathrm{k}^{\mathrm{h} l o s i t t s i}$ \\
1PI & $\mathrm{k}^{\mathrm{h} l o s i d i}$ & $\mathrm{k}^{\mathrm{h} l o s i t d i}$ \\
1PE & $\mathrm{k}^{\mathrm{h} l o s i n k u}$ & $\mathrm{k}^{\mathrm{h} l o s i t t o k o}$ \\
\hline 2SG & $\mathrm{k}^{\mathrm{h} l o s i n a}$ & $\mathrm{k}^{\mathrm{h} l o s i t n a}$ \\
2DU & $\mathrm{k}^{\mathrm{h} l o s i t s i}$ & $\mathrm{k}^{\mathrm{h} l o s i t t s i}$ \\
2PL & $\mathrm{k}^{\mathrm{h} l o s i n n i}$ & $\mathrm{k}^{\mathrm{h} l o s i t n i}$ \\
\hline 3SG & $\mathrm{k}^{\mathrm{h} l o s i}$ & $\mathrm{k}^{\mathrm{h} l o s i t d a}$ \\
3DU & $\mathrm{k}^{\mathrm{h} l o s i n t s i}$ & $\mathrm{k}^{\mathrm{h} l o s i t t s i}$ \\
3PL & $\mathrm{k}^{\mathrm{h} l o s i m i}$ & $\mathrm{k}^{\mathrm{h} l o s i m r i}$ \\
\hline
\end{tabular}

Table 4. -si verb paradigm

\subsection{Base verbs that undergo derivation in -si}

The most common base verbs found to undergo derivation with $-s i$ are transitive verbs. This is unsurprising considering that the main function of $-s i$ is to reflexivize verbs, thereby reducing their valence. A typical example is found in the verb khremmu $|\mathrm{khrep}|$, 'to cover with something' which has a derived form khremsimu |khrep-sit|, 'to cover oneself'.

Derivation with $-s i$ is quite productive for transitive base verbs; for any given verb with semantics that lend themselves to reflexivization, the derived form can generally be found. The derived verbs are not universally reflexive, as shall be discussed in 3.3. below, but reflexives are the most frequently represented category among derived verbs in my corpus.

A few intransitive verbs have also been found to undergo -si derivation, resulting in much more subtle semantics than are found with transitive base verbs as input. However, there appears to be less consensus about these intransitive base/derived verb pairs: one speaker claims the existence of a (semantically indistinguishable) јетти |jem|/jemsimu |jem-sit| pair (both 'to stand'), whereas another claims that only jemsimu exists. Derivation with intransitive verbs as an input is further discussed in 3.3.5 below.

\footnotetext{
${ }^{4}$ The underlying morpheme is -sit, which has allomorphs -si, -sin, and -sit. The allomorphs are the same as found with intransitive $-t$ stem verbs, but their distribution of allomorphs is a little different; for $\mathrm{a}_{\mathrm{f}}-\mathrm{t}$ verb, we would expect $-\sin$ for $2 \mathrm{du}$ and $3 \mathrm{pl}$ non-past and $-s i$ for $2 \mathrm{du}$ non-past, whereas Table 4 shows that we have $-s i$ for the first two, and $-\sin$ for the last. This suggests that the morpheme has grammaticalized.
} 
We also find what we shall call deponent verbs: the term is used here as in Kemmer (1993: 22) to refer to verbs which occur with -si and present semantics consistent with reflexive (and related) derivation, but for which no base verb is synchronically attested. Table 5 presents some of these verbs as found in Thulung. It is interesting to note that in some cases, other languages have verbs cognate with the expected (but unattested) base verb: Khaling for example has the roots |tsemt| 'play with' and |ghremt| 'disgust', contrasting with the cognate Thulung deponents in Table 5 below.

\begin{tabular}{cc}
\hline infinitive form & meaning \\
\hline ph $\Lambda$ simu & to wear, put on clothes \\
\hline hisimu & to turn head or body \\
\hline khusimu & to wear on head \\
\hline khlysimu & to wear on feet \\
\hline yesimu & to rest \\
\hline yosimu & to wake up \\
\hline tsamsimu & to play \\
\hline bhrosimu & $\begin{array}{c}\text { to come out, to come } \\
\text { undone, come loose }\end{array}$ \\
\hline ghramsimu & to be disgusted \\
\hline
\end{tabular}

Table 5. Defective verbs with -si

\subsection{Semantico-syntactic categories of -si verbs}

Verbs which have undergone derivation with $-s i$ have reduced valence compared with the base verbs they are derived from. Among derived verbs, we find several configurations, which I express as formulas showing the change in argument marking in the base (to the left of the ">") and in the derived verb (to the right of the " $>$ "):

1) A, P > S: both the agent and patient of the base verb are reduced to a single $S$, which is semantically agent and patient of the same action at the same time. This results in a reflexive reading of the derived verb.

2) $A, P>S$ (non-singular): the $A$ and $P$ of the base verb are reduced to a single $S$, but unlike in the reflexive interpretation of $-s i$, the reciprocal interpretation implies the existence of several referents that act upon each other either simultaneously or in turn.

3) $\mathrm{A}>\mathrm{S}, \mathrm{P}>0$ : The base verb $\mathrm{A}$ becomes the derived verb's $\mathrm{S}$, and the $\mathrm{P}$ disappears or becomes an adjunct. This results in an antipassive reading for the derived verb.

4) $\mathrm{A}>0, \mathrm{P}>\mathrm{S}$ 
The $\mathrm{A}$ is removed during the derivation, and the $\mathrm{P}$ takes on the role of $\mathrm{S}$. Note that the A is not recoverable semantically or syntactically. This results in an anticausative reading for the derived verb.

Examples of each of these verb types shall be given below.

\subsubsection{Reflexive reading of verbs derived in - si}

Of the verbs derived in -si the largest category found are reflexives, including grooming verbs. The $\mathrm{A}$ and $\mathrm{P}$ of the base verb both have the same referent after derivation, with the action being carried out on oneself.

This is for example the case with the verb thısimu |thık-sit|, 'to hide (self)':

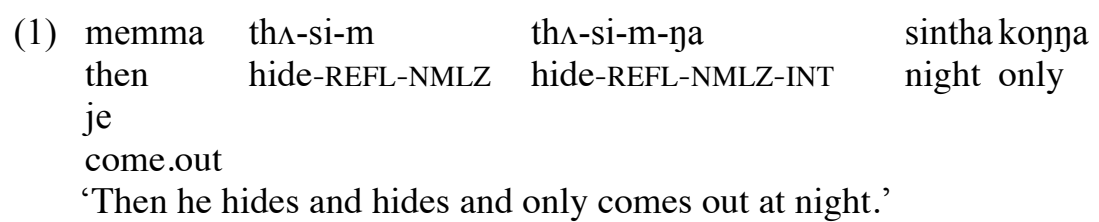

This contrasts with the base verb thımu|thık|, 'to hide':
(2) tshimori wo thık-a me-gonu-na broom also hide-2SG.IMP that-inside-INT 'Hide the broom in there as well.'

A number of grooming verbs are derived with $-s i^{5}$. They are show in Table 6 along with their base verbs.

\begin{tabular}{llll}
\hline \multicolumn{1}{c}{ grooming verb } & \multicolumn{1}{c}{ meaning } & \multicolumn{1}{c}{ base verb } & \multicolumn{1}{c}{ meaning } \\
\hline selsimu |sel-sit| & wash (oneself) & selmu |sel| & wash \\
\hline blansimu |blat-sit| & dry oneself & blanmu |blat| & dry in sun \\
\hline dynsimu |dyt-sit| & comb one's hair & dynmu |dyt| & comb \\
\hline hursimu |hur-sit| & wash one's hair & hurmu |hur| & wash hair \\
\hline khursimu |khur-sit| & shave & khurmu |khur| & shave off \\
\hline
\end{tabular}

Table 6. Grooming verbs in -si and their bases.

\subsubsection{Reciprocal reading of verbs derived in - si}

For verbs with non-singular arguments where each argument acts simultaneously as the $\mathrm{A}$ and $\mathrm{P}$ in individual events that make up a composite action, a possible interpretation is as a reciprocal. This is a highly specific situation, and in most cases, it coexists with a parallel situation whereby a verb with a non-singular argument has a reflexive interpretation. This is seen for example with tsamsimu, 'to play': for non-singular arguments, the interpretation can be either 'to play with each other' or 'to play alone (but as part of a group doing the same)'.

${ }^{5}$ A few additional verbs are considered grooming verbs but they are deponent, with no corresponding base verb attested. 
The following pair of examples shows the reciprocal interpretation found with balsimu |bal-sit|, 'to be intertwined':

(3) memim twatwap bal-si-mi

3PL each intertwine-REFL-3PL

'They are intertwined/they are tangled together.'

This is contrasted with balmu $\mid$ bal|, 'to intertwine':

(4) gui czepa riba bal-i $\mathrm{h} \Lambda \mathrm{i}$

1PI good rope intertwine-1PI EMPH

'Let's make good rope, OK.'

Another example of a verb for which there is a reciprocal interpretation is phwasimu |phwak-sit|, 'to separate':

(5) mertsip mamtha phwa-sit-tsi

that-DU last.year separate-REFL-3DU.PST

'They separated from each other last year.'

This is contrasted with the base verb phwamu |phwak|, 'to separate':

(6) medda ns-le tsetstse kwalba be-tsi-m-ka

\begin{tabular}{llll} 
there & $2-\mathrm{CL}$ & child & \multicolumn{1}{c}{ fight } \\
go & $1 \Lambda$-yro & ma phwak-totsi & do-3DU.PST-NMLZ-ERG \\
1SG & go-1SG.PST & CONJ & separate-1SG>DU.PST
\end{tabular}

'As the two children were fighting, I went over there and separated them.'

The reciprocal interpretation of $-s i$ derived verbs depends very much on their semantics and is not productive. There is a distinct productive process for making reciprocal verbs in Thulung: verb root-be + bomu $^{6}$

rem-be bomu, 'to look at each other' (remmu, 'to look')

jal-be bomu, 'to hit each other' (jalmu, 'to strike')

jen-be bomu, 'to call each other'(jenmu, 'to call')

Note that for verbs for which the $-s i$ derivation results in a reciprocal interpretation, the -be bomu construction is blocked: tsamsimu, 'to play (alone or together)' but *tsambe bomu.

\subsubsection{Antipassive reading of verbs derived in - si}

For some verbs, the base verb A becomes the derived S, with the P deleted or becoming an adjunct (via comitative marking).

For the verb mimsimu |mim-sit|, 'to think, to reflect', the $\mathrm{P}$ deletion results in a more abstract interpretation of the verb:

\footnotetext{
${ }^{6}-b e$ is one of the stems of the verb 'to do'; bomu is the infinitive form of the same verb.
} 


$\begin{array}{llcccc}\text { tsim } & \text { me-tsip } & \text { ne } & \text { si-da } & \text { rwak-tsi } & \text { ma mim-sik- } \\ \text { that-DU } & \text { FOC } & \text { die-3SG.PST say-3DU } & \text { CONJ } & \text { think-REFL-3DU- } \\ \text { NMLZ } & & & & \end{array}$

'They said "he is dead" and thought.'

This contrasts with the underived base verb mimmu $|\mathrm{mim}|$, 'to think about something':

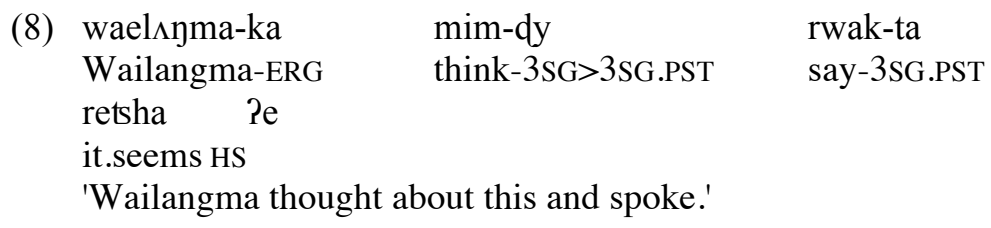

An example which shows the demotion of P is ghramsimu, 'to be disgusted', where the $\mathrm{P}$ is marked as an adjunct using oblique case (in this case, the comitative marker $-n u \eta$ ), as seen in 9:
(9) go bira-nuy ghram-si-nu $1 \mathrm{SG}$ leech-COM be.digusted-REFL-1SG
'I am disgusted by leeches.'

Emotion and cognition verbs are well-represented in this category, with the $\mathrm{S}$ often being an experiencer.

\subsubsection{Anticausative use of verbs derived in -si}

An anticausative reading ensues when derivation results in the deletion of the original A, with the base P becoming the derived verb $\mathrm{S}$. After deletion, the A is irretrievable semantically (as well as syntactically).

For the verb tsarsimu |sar-sit|, 'to fall down', for example, there is no way to retrieve what set the action in motion:

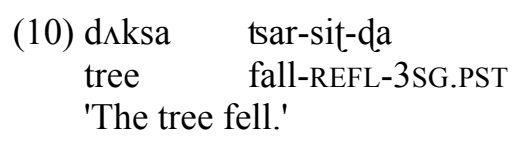

Note that the same verb is used when warning someone not to fall, and that in this case as well it is an anticausative, as there is no retrievable agent:
(11) tsar-si-na
fall-REFL-2SG
$\mathrm{h} \Lambda \mathrm{i}$
'You're going to fall!'
EMPH

The base verb is tsarmu |tsar|, 'to make fall', where the instigator of the action is clear as the A: 

(12) go
gai-lai
ut-to
ma tsar-to
1SG cow-DAT push-1SG.PST
CONJ make.fall-1SG.PST

'I pushed the cow and made it fall.'

\subsubsection{Derivation in -si from an intransitive base verb}

The semantics of verbs derived from an intransitive are much closer to those of the base verb, and the differences are often quite subtle. The following verb pairs show to extent to which this is true:

krumu |kruk|, 'to roar, to make a roaring sound'

krusimu |kruk-sit|, 'to roar to express an emotion'

lamdimu |lamdi|, 'to walk'

lamdisimu |lamdi-sit|, 'to walk like', illustrated in 13:

(13) tsetstse-mim

child-PL

sokse hoyna

monkey like.this

'The children must walk like monkeys.' $\begin{array}{ll}\text { lamdi-si-mu } & \text { basi } \\ \text { walk-REFL-INF } & \text { OBL }\end{array}$

To a certain extent, derivation from intransitives results in semantics analogical to the relationship between transitives and antipassives; there is a generalization of the meaning (for antipassives this is by virtue of removing the $\mathrm{P}$; for intransitives as well, the verb is distanced from its interpretation relative to a single, specific S), although this is not always true of the verb pairs. No differences are noted between the following verbs in each pair:

dzinmu |dzit|/dzisimu |ckit-sit|, 'to get wet'

g^nти $|\mathrm{g} \wedge \mathrm{n}| / g_{\wedge} \wedge \operatorname{simu} \mid \mathrm{g} \wedge \mathrm{n}$-sit|, 'to sit'

јетти |jem| /jemsimu |jem-sit|, 'to stand'

\section{DERIVATION WITH $-S$}

The discussion now turns to $-s$, which in some cases can be seen to be a reflexive suffix and in others, an inflectional element which reflects no-longer productive derivational processes. A number of verbs, mostly intransitive, are found to have certain forms in which an $-s$ appears before the agreement marker. The morpheme is not easy to associate with any particular derivational process, and on closer inspection it becomes apparent that the reason for this is that $-s$ has several different (albeit related) origins.

\subsection{Paradigm for verbs with suffix - s}

As seen in Table 7, verbs which take $-s$ (whether derivational or other, as will be discussed below) have paradigms in which the distribution of $-s$ is limited to 1PI and 3SG (as well as 2SG imperative forms, which are not shown in Table 7). 


\begin{tabular}{|c|c|c|}
\hline lımu $\left|l_{\wedge} k s\right|$, 'to go' & NPST & $P S T$ \\
\hline $1 \mathrm{SG}$ & $1 \Lambda-\eta \mathrm{u}$ & $1 \Lambda$-pro \\
\hline 1DI & $1 \Lambda$-tsi & $1 \Lambda \mathrm{k}-\mathrm{tsi}$ \\
\hline $1 \mathrm{DE}$ & $1 \Lambda$-tsuku & 1几k-tsoko \\
\hline $1 \mathrm{PI}$ & $1 \wedge \mathrm{ks}-\mathrm{i}$ & $1 \Lambda \mathrm{s}-\mathrm{di}$ \\
\hline $1 \mathrm{PE}$ & $1 \Lambda-\mathrm{ku}$ & lnk-toko \\
\hline $2 \mathrm{SG}$ & $1 \Lambda$-na & lık-na \\
\hline $2 \mathrm{DU}$ & $1 \Lambda-$ tsi & $1 \Lambda \mathrm{k}-\mathrm{tsi}$ \\
\hline $2 \mathrm{PL}$ & lıni & lık-ni \\
\hline $3 \mathrm{SG}$ & $1 \Lambda$ & lns-da \\
\hline $3 \mathrm{DU}$ & $1 \Lambda$-tsi & $1 \Lambda \mathrm{k}-\mathrm{si}$ \\
\hline $3 \mathrm{PL}$ & $1 \Lambda-\mathrm{mi}$ & $1 \Lambda$-mri \\
\hline
\end{tabular}

Table 7. Distribution of the -s suffix

The limited distribution of an element related to a reflexive morpheme is found in some other Rai languages. Opgenort (2005: 164) writes of Jero: "The suffix $<$-si $>$ marks a middle scenario in third person singular forms, in which the middle suffix precedes the phonologically empty second and third person singular agreement morpheme. [...] The middle morpheme does not occur in the other forms of the middle paradigm. This restricted distribution is also found in Wambule." This limited distribution in both languages is evidence of language change for Opgenort (2004: 306): "The restricted distribution of the Wambule middle marker $<$-si $>$ might be explained by stating that Wambule is somewhere in the process of developing from a language such as Bahing, which has a middle marker in all finite middle forms, towards a language in which a middle marker is absent."

\subsection{Derivational nature of $-s$}

The nature of $-s$, which always occurs with the distribution found in Table 7 , is not immediately apparent, the reason for this being that it has several different origins. These are: 1) as a variant of the reflexive morpheme $-s i$ (see 4.2.1);2) as the obligatory root final for some verbs, reflecting earlier derivational morphology which has been incorporated into the verb stem (see 4.2.2); and 3) as an optional root final for some verbs (see 4.3.3).

\subsection{1. $-s$ as a variant of $-s i$}

One very common source of $-s$ is as a phonologically reduced variant of $-s i$, in $1 \mathrm{PI}$ and 3SG forms of reflexive verbs. This is illustrated with examples 14 and 15 .
(14) me
tsyplo-ra
dzam ne al-s-ta
retsha
that clay.pot-LOC
rice FOC spill-REFL-3SG.PST it.seems
'It seems that the food in the pot spilled.'

In this sentence, the verb could also have been alsidda, from alsimu |al-sit|, 'to be spilled' (derived from almu $|\mathrm{al}|$, 'to spill') 


$\begin{array}{lllll}\text { (15) diphu } & \text { ne } & \text { me } & \text { dzau ne } & \text { khlo-s-ta } \\ \text { later } & \text { FOC } & \text { that } & \text { Jau FOC } & \text { return-REFL-3SG.PST } \\ \text { ma } & \text { rok-ta } & & \text { retsha } & \\ \text { CONJ } & \text { come-3SG.PST } & \text { it.seems } & \\ \text { 'Then later Jau returned.' } & \end{array}$

In 15, khlosta is a phonologically reduced form of the reflexive verb: khlosidda could be substituted for khlosta, the former being the standard 3SG.PST form of khlosimu |khlok-sit|, 'to return', the verb being derived from khlo:mu |khlok|, 'to return something'.

Speakers do not consider the reduced form in -s as good a form as the unreduced version in $-s i$. Yet considering the frequency of use of $-s$ forms which are clearly derivational, -s can be considered part of the derivational apparatus of Thulung, with the same semantico-syntactic categories described in 3.3. above. ${ }^{7}$

The use of $-s$ as an equivalent for $-s i$ is almost always possible. I did however find that speakers were more resistant to accept it when there was a phonologically identical form resulting from a distinct (non-reflexive) verb: the verb bhrımu |bhrss|, 'to taste good' has a 3SG.PST form bhrısta. The verb bhrısimu |bhrıs-sit|, 'to enjoy oneself, be happy', which one would expect to also have a variant 3SG.PST form in -sta, bhrssta, but in fact only bhrssidda is considered acceptable. If the form in -s were available as a 3sg.pst variant of bhrssidda, this would leave bhrssta with two interpretations with distinct semantics. As a result, bhrusta is not available as a variant for bhrusidda.

\subsection{2. $-s$ as an obligatory verb root final}

As mentioned above, a number of verbs which are not overtly reflexive (or sharing related functions) always have $-s$ forms for $3 \mathrm{SG}$ and 1 PI. These verbs are considered to have $-s$ as one of their underlying root finals, even though the $-s$ only surfaces partially. Table 8 shows a paradigm for a verb with final $-s$.

\footnotetext{
${ }^{7}$ For many years I mistook the productive derivational $-s$, which is a reduction of $-s i$, to be a distinct derivational morpheme. My analysis was that, because of its distribution in certain semantic areas of the language, $-s$ was a middle marker, to be contrasted with the more productive reflexive marker $-s i$. I currently believe that analysis to have been mistaken, based on what I now believe to be a conflation of more than one $-s$ morpheme in Thulung.
} 


\begin{tabular}{|c|c|c|}
\hline $\begin{array}{c}s \wedge m u|s \wedge s|, \\
\text { heal' }\end{array}$ & NPST & PST \\
\hline $1 \mathrm{SG}$ & $\mathrm{s} \Lambda-\eta \mathrm{u}$ & SA-nro \\
\hline 1DI & $\mathrm{S} \Lambda$-tsi & $\mathrm{s} \Lambda$-ttsi \\
\hline $1 \mathrm{DE}$ & s $\Lambda$-tsuku & $\mathrm{s} \Lambda$-ttsolo \\
\hline 1PI & SAS-i & $\mathrm{s} \Lambda \mathrm{s}-\mathrm{ti}$ \\
\hline $1 \mathrm{PE}$ & $\mathrm{s} \Lambda-\mathrm{ku}$ & S $\Lambda$-ttoko \\
\hline $2 \mathrm{SG}$ & $\mathrm{s} \Lambda$-na & $\mathrm{s} \Lambda$-nna \\
\hline $2 \mathrm{DU}$ & s $\Lambda$-tsi & $\mathrm{s} \Lambda$-ttsi \\
\hline $2 \mathrm{PL}$ & S $\Lambda$-ni & $\mathrm{s} \Lambda$-nni \\
\hline $3 \mathrm{SG}$ & $\mathrm{S} \Lambda$ & s $\Lambda$ S-ta \\
\hline $3 \mathrm{DU}$ & $\mathrm{s} \Lambda$-tsi & $\mathrm{s} \Lambda$-ttsi \\
\hline $3 \mathrm{PL}$ & $\mathrm{s} \Lambda$-mi & $\mathrm{s} \Lambda$-mri \\
\hline
\end{tabular}

Table 8. Paradigm for an - s stem verb (with - s stems highlighted)

Thulung verbs of this category can be considered to have a $(C) V\left(C_{f}\right) s$ root. In other words, the verbs in this class will have two finals: a $\mathrm{C}_{\mathrm{f}}$ as well as an $-s$. An exception is found in verbs which have only an $-s$ as a root final (such as $|\mathrm{s} \Lambda \mathrm{s}|$ in Table 8), which have (C)Vs roots. Note, however, that $-s$ is not listed as one of the possible $\mathrm{C}_{\mathrm{f}}$ 's for Thulung ${ }^{8}$ (section 2), and that having two final consonants constitutes a deviation from the standard Kiranti verb root template of $(C) \mathrm{V}(\mathrm{C})$.

This suggests that the verbs described in this category are made up of a templatically correct, standard verb root, with a single Cf and an additional $-s$. The most plausible origin for the additional $-s$ is as an erstwhile reflexive suffix: this is suggested by the fact that such verbs tend to be intransitive, and furthermore that body action verbs are well represented among them: 'heal' $(|\mathrm{s} \Lambda \mathrm{s}|)$, 'itch' $(|\mathrm{sys}|)$, 'laugh' $(|\mathrm{ris}|)$, 'vomit' $(|\mathrm{phos}|)$, 'fart' $(|\mathrm{ses}|)$, 'defecate' (|es $\mid)$, 'urinate' (|sars $\mid)$, 'sleep' $(|\Lambda \mathrm{ms}|)$, 'be born' $(|\mathrm{g} \Lambda \mathrm{ks}|)$.

We can hypothesize that the derivational suffix was gradually bleached of its reflexive semantics, explaining how it is possible that it can be found with verbs with semantics which have nothing to do with reflexivity, and that it can even been found with a number of transitive verbs. The semantic bleaching may be a reason behind the fact the $-\mathrm{s}$ is found in incomplete paradigms, as bleaching might affect the productivity of the morpheme.

\subsection{3. $-s$ as an optional verbal element}

Some verbs have an optional $-s$ in $3 \mathrm{SG}$ and 1 PI forms. ${ }^{9}$ Roots for such verbs are listed as $(\mathrm{C}) \mathrm{V}(\mathrm{C})(\mathrm{s})$, reflecting the optionality of the $-s$. One such verb is gimu

\footnotetext{
${ }^{8}$ Note however that it is not unheard of to have verbs ending in $-s$ in Rai languages; Limbu for

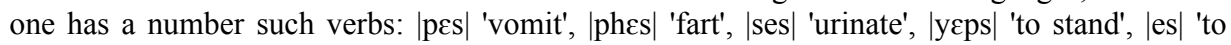
defecate', |sos| 'to itch', |nams| 'to smell' (taken from Michailovsky's online Limbu dictionary, lacito.vjf.cnrs.fr/pangloss/dico/). Note however the similarity with cognate Thulung verbs, and the possibility that the Limbu $-s$ has the same source as in Thulung.

${ }^{9}$ I have found no evidence of any environment which dictates whether or not the optional -s surfaces in these forms: I have heard speakers say the 3SG form of a verb with no -s in one sentence, and say it again in the next sentence with an -s. Both forms are in free variation for verbs with optional -s.
} 
$|\mathrm{yi}(\mathrm{s})|$, 'to fear' which can have 3SG.PST forms yidda or yista, both being interchangeable:

(16) meram-ka wo that-ERG also phıl-mu pis-ta 'He was afraid to cut [during a sacrifice].'

Verbs in this category have the same behavior as their non-optional equivalents discussed in 4.2.2, with the main difference that the form in $-\mathrm{s}$ is a variant to the standard stem and not an obligatory part of the verb.

The phenomenon of the 'additional -s', whether optional or obligatory, was originally described by Allen (1975), who describes three different categories of occurrences of -s in the verbal system:

1) as the final consonant of a verb stem class (1975: 62); examples given in the text are loas- 'see' and səs- 'be cured': these are verbs which always have an s in specific parts of the conjugation paradigm (3SG and 1PI, as well as imperatives), alternating with an open stem elsewhere. The $\mathrm{s}$ is part of the verb root morphology, and is not a suffix.

2) as an obligatory additional $-s$ in some verbs (in addition to their final consonants), leading to "distinct stem classes" [distinct from the stem class with $\mathrm{s}$ as consonant final] (1975: 71). Examples are verbs in - $m s$ (such as dams'mislay'), - $p s$ (such as caps- 'be able'), - $k s$ (such as koks- 'raise'). It is not clear whether Allen considers the $-s$ to be a suffix, or part of the verb root (judging from his term "additional obligatory", it seems to be the former), but either way, the $\mathrm{s}$ is always present in this category of verbs.

3 ) as an optional additional $-s$ (1975: 71). Verbs in this category are listed in Allen with parentheses around the $\mathrm{s}$ following the stem final consonant (a convention I have adopted above).$^{10}$ Allen does not say much about these, except to give statistics about what kinds of stem consonants they occur with.

For both s stem class verbs (category 1 above) and those with an obligatory additional s (category 2 above), Allen points out a very high proportion of intransitive verbs in the classes. "Some $70 \%$ of s stem verbs take intransitive endings. [...] Other stem consonants range between 10\% and 30\% intransitives. In other words there is a strong tendency for s stem verbs to be intransitive. [...] The same may be true of verbs where the additional $\mathrm{s}$ is an obligatory part of the stem." (1975: 131)

In my analysis, Allen's categories 1 and 2 are subsumed into a single category (4.2.2, obligatory final) but refer to different types of original input verbs: verbs of the form (C)Vs are those for which the original verb had an open-syllable root, to which the $-s$ was suffixed and then eventually was reinterpreted as part of the verb root; these are Allen's 'category 1' verbs. Allen's second category is made up of verbs which originally had a Cf, unlike open-syllable verbs, resulting in a

\footnotetext{
${ }^{10}$ Verbs with optional additional $\mathrm{s}$ in Allen's glossary are the following: ək-/əks- pull out; hel(s)- divert (irrigation stream); hil(s)- mash, squash; hok(s)- peel, strip; kit(s)- cut up; kleot(s)- make mistake; nat(s)- crush; riup(s)- cut down; sar(s)- urinate; tat(s)- scrape out; that(s)- take out
} 
double root-final consonant when the derivational suffix became integrated into the verb root. In other words, these two categories of verbs have undergone the same processes, just with different verb types as original inputs.

Allen makes a connection between verbs with $-s$ and the middle voice. He suggests that a possible diachronic source for verbs in the s stem class and verbs with "additional obligatory s" is verbs "compounded with si(t)-" (1975: 131), of which he says that "the effect of adding [aspectual -sit- ${ }^{11}$ to a transitive verb is often similar to that of changing a verb from active to middle voice in classical Greek. The resulting compounding is often intransitive, but by no means necessarily." (1975: 74). It is not clear whether at the time of his fieldwork, Thulung speakers already used $-s$ as a variant of the reflexive marker, but the diachronic connection Allen posits between $-s$ and reflexive (in his words 'aspectual') -si is reinforced by current usage.

\subsection{Occurrence with transitive verbs}

A somewhat surprising feature of $-s$ as a final, whether optional or obligatory, is its occurrence with certain transitive verbs. This pattern does not apply to $-s$ as a variant for reflexive $-s i$. We established in 4.2.2 that $-s$ was an erstwhile valencereducing derivational morpheme, and it is therefore no surprise that in many cases, it occurs with intransitive verbs. Nonetheless, some Thulung verbs with $-S$ are transitive, with the same configuration as discussed in 4.2.2. and 4.2.3.: for some verbs, it is obligatory, for others, it is optional.

Some examples of transitive $s$-marked verbs follow.

In (17), we have the transitive verb $|\mathrm{k} \wedge \mathrm{ks}|$, 'to give birth':

(17) me $\mathrm{p} \Lambda$ tshi tsy tsıyrapheri gupsykıs-ty that after thorn after again tiger give.birth-3SG $>3 \mathrm{SG}$.PST

Pe

HS

'Then after the thorn, she gave birth to the tiger.'

The form in (18) of the verb $|\mathrm{d} \Lambda \mathrm{k}(\mathrm{s})|$ 'to drop' could alternately be $q_{\Lambda} k t y$.

(18) me bhale ne u-pasirym d $\Lambda$ s-ty that cock FOC 3sG.POSS-feather drop-3sG $>3$ SG.PST 'That cock dropped his feather.'

In (19), |thyr(s)| 'to send' can have the forms thyrsty or thyrry.

(19) ko-le khlea-lai thyrs-ty retsha ?e one-CL dog-DAT send-3SG $>3$ SG.PST it.seems HS 'One day, he sent a dog [outside the hole].'

\footnotetext{
${ }^{11}$ This morpheme is the reflexive marker -si discussed earlier.
} 
In considering how the $-s$ final came to occur with transitive verbs, one helpful path is to look at intransitive equivalents of transitive verbs in $-s$. Some of these pairs are shown in Table 10.

\begin{tabular}{|c|c|c|c|}
\hline$v t$ verb in $-s$ & meaning & vi equivalent & meaning \\
\hline $\mathrm{k} \Lambda: \mathrm{mu}|\mathrm{k} \wedge \mathrm{ks}|$ & 'to give birth' & $\mathrm{g}_{\Lambda \mathrm{mu}}|\mathrm{g} \Lambda \mathrm{ks}|$ & 'to be born' \\
\hline dymmu |dyms| & 'finish' & dymmu $\mid$ dyms $\mid$ & 'become' \\
\hline tsammu |tsaps| & 'be capable of' & dzhammu |dzhaps| & 'be able to' \\
\hline almu $\mid$ als & 'drop' & almu $|\operatorname{al}(\mathrm{s})|$ & 'fall' \\
\hline ts $\Lambda: \mathrm{mu} \mid$ ts $\Lambda \mathrm{k}(\mathrm{s}) \mid$ & 'snap long things' & dzımu $|\mathrm{d} \wedge \mathrm{s}|$ & 'be broken' \\
\hline ammu $|\operatorname{am}(\mathrm{s})|$ & 'put to sleep' & $\Lambda \mathrm{mmu}|\Lambda \mathrm{ms}|$ & 'sleep' \\
\hline dammu $|\operatorname{dam}(\mathrm{s})|$ & 'lose' & dammu |dams| & 'disappear' \\
\hline
\end{tabular}

Table 10. Some transitive verbs with - s and their intransitive equivalents

While there are not many such pairs, because not all transitive $-s$ verbs have intransitive equivalents, the ones that are found in Thulung show that the $-s$ is also present on the intransitive member of the pair. This suggests a possible explanation for the presence of the $-s$ on some transitive verbs, namely as a derivational trace of intransitivity on the verb which was the input to a valenceincreasing operation resulting in the current transitive verb.

We can posit a first stage during which transitive verbs underwent derivation with the reflexivizing suffix $-s$. While the process is no longer productive with $s$, this is similar to the productive derivation with $-s i$ leading to reflexive (and related, see section 3.3 for examples of current range) interpretations.

The result would have been a number of verbs with reflexive semantics and intransitive argument structure, with a suffix $-s$ on their roots, which could then be used, like any other intransitive verb ${ }^{12}$, as the input for causative/applicative derivational processes via prefixes (such as those described for example in LaPolla 2003 or more specifically for Kiranti in Michailovsky 1999). The $-s$ that was part of the input root would have been preserved, leading to transitive verbs which, like their intransitive equivalents (from which they were derived), also had an $-s$ on the root.

\footnotetext{
${ }^{12}$ The equation of reflexive and intransitive as inputs for derivational processes requires some explanation: LaPolla (1995: 1169ff, 2004) discusses the connection between reflexive, middle and 'stativizing' markers in Dulong, showing how intransitive attributive predication is marked with reflexive/middle morphology as an extension of the latter's 'diminishing the conceptual separation of the events and participants involved'.

On a different front, Palancar lays out the differences between a series of nasal morphemes in Otomi with different functions but a common source. He presents a detransitivizer, 'nasal morpheme similar in form to the middle marker' (2006: $621 \mathrm{ff}$ ), with examples which are very similar to what has been described in 3.3.3 as the antipassive reading of the reflexive marker in Thulung. While in Otomi a clear case is made for these being distinct morphemes (as Otomi middle-marked verbs can be both transitive and intransitive, whereas detransitiver-marked verbs can logically only be intransitive, this is not the case for -si marked verbs in Thulung which (whatever their reading, be it reflexive, antipassive, etc) can only be intransitive.
} 
These pathways are hypothetical but they do provide a way to account for the $-s$ being found with transitive verbs, especially in light of some of these verbs still existing as part of intransitive-transitive verbs pairs, both with the $-s$. This appears to be yet another instance of the multi-layered derivational history of Kiranti verbs which can be read in the morphology of the verbs.

\section{CONCLUSION}

In this article I have described the distribution of two morphemes, $-s i$ and $-s$, both having reflexivizing functions, but also, in the case of $-S$, as a suffix bleached of its valence-reducing function and assimilated, to different degrees depending on the verb, into verb root morphology. This article also illustrates the presence of $-S$ with certain transitive verbs, and proposes an explanation for this phenomenon which is compatible with the derivational nature of $-s$.

\section{GLOSS ABBREVIATIONS}

\begin{tabular}{|l|l|}
\hline CL & classifier \\
\hline COM & comitative \\
\hline CONJ & conjunction \\
\hline DAT & dative \\
\hline DE & dual exclusive \\
\hline DI & dual inclusive \\
\hline DU & dual \\
\hline EMPH & emphatic \\
\hline ERG & ergative \\
\hline FOC & Focus \\
\hline HS & hearsay \\
\hline IMP & imperative \\
\hline INF & infinitive \\
\hline
\end{tabular}

\begin{tabular}{|l|l|}
\hline INT & intensifier \\
\hline LOC & locative \\
\hline NMLZ & nominalizer \\
\hline NPST & non-past \\
\hline OBL & obligation \\
\hline PE & plural exclusive \\
\hline PI & plural inclusive \\
\hline PL & plural \\
\hline POSS & possessive \\
\hline PST & past \\
\hline REFL & reflexive \\
\hline SG & singular \\
\hline
\end{tabular}

\section{REFERENCES}

Allen, N.J. 1975. Sketch of Thulung grammar, with three texts and a glossary. Ithaca: China-Japan Program.

Jacques, Guillaume, Lahaussois, Aimée, Michailovsky, Boyd, and Rai, Dhan Bahadur. 2012. An overview of Khaling verbal morphology. Language and Linguistics 13(6): 1095-1170.

Kemmer, Suzanne. 1993. The middle voice (Typological Studies in Language 23). Amsterdam: John Benjamins. 
Lahaussois, Aimée. 2011. The Thulung Rai verbal system: an account of verb stem alternation. Cahiers de Linguistique Asie Orientale 40(2): 189-224.

LaPolla, Randy. 1995. On the utility of the concepts of markedness and prototypes in understanding the development of morphological systems. Bulletin of the Institute of History and Philology 66(4): 1149-1185.

LaPolla, Randy. 2003. Overview of Sino-Tibetan morphosyntax. In G. Thurgood and R. LaPolla (eds.), The Sino-Tibetan languages (Routledge Language Family Series 3), 22-42. London and New York: Routledge.

LaPolla, Randy J. with Yang Jiangling, 2004. Reflexive and middle marking in Dulong-Rawang. Himalayan Linguistics 2: 1-13.

Michailovsky, Boyd. (1975) Notes on the Kiranti verb. Linguistics of the TibetoBurman Area 2(2): 183-218.

Michailovsky, Boyd. 1999. Tibeto-burman dental suffixes: Evidence from Limbu (Nepal). In Y.P. Yadav \& W.W. Glover (eds.), Topics in Nepalese linguistics, 478-494. Kathmandu: Royal Nepal Academy

Michailovsky, Boyd. Limbu dictionary. lacito.vjf.cnrs.fr/pangloss/dico/, accessed 1 June 2015.

Opgenort, Jean Robert. 2004. A grammar of Wambule. Grammar, lexicon, texts and cultural survey of a Kiranti tribe of eastern Nepal. Brill's Tibetan Studies Library. Languages of the Greater Himalayan Region, 2. Leiden: Brill.

| Opgenort, Jean Robert. 2005. A grammar of Jero. With a historical comparative study of the Kiranti languages. Brill's Tibetan Studies Library. Languages of the Greater Himalayan Region, 3. Leiden: Brill.

Palancar, Enrique. 2006. Intransitivity and the origins of middle voice in Otomi. Linguistics 44(3): 613-643.

Author's address

Aimée Lahaussois

Histoire des théories linguistiques

UMR 7597 CNRS/Université Paris Diderot

Case 7034, 5 rue Thomas Mann

75205 Paris Cedex 13, France

aimee.lahaussois@linguist.univ-paris-diderot.fr 